\title{
Uso dos Recursos Tecnológicos Atuais e sua contribuição no processo de Ensino-Aprendizagem na Escola Municipal Érico Veríssimo, Simões-PI
}

\author{
Nerivaldo Brás de Carvalho ${ }^{1}$; Anna Christina Farias de Carvalho ${ }^{2}$
}

\begin{abstract}
Resumo: O objeto de análise deste trabalho foi o uso das tecnologias atuais na Escola Érico Veríssimo município de Simões - PI e tem como objetivo estudar as contribuições dos recursos tecnológicos na escola, reconhecendo a importância desses recursos para a melhoria da qualidade do ensino aprendizagem. Analisar as contribuições dos mesmos para uma aprendizagem significativa, identificando os desafios dos professores e alunos diante do uso dessas tecnologias como mecanismo de ensino. Esse trabalho se constitui em uma pesquisa de campo e bibliográfica. Como ponto de partida o estudo foi fundamentado nas ideias de diferentes autores que versam a respeito do tema, dentre esses estudiosos temos Kiso (2007), Moran (2000) e Sousa (2010). Durante a pesquisa pode-se verificar que é possível inserir as tecnologias atuais nas aulas; bem como, incluir no planejamento o uso dessas ferramentas, inovando assim, a metodologia utilizada pelos educadores, fazendo cooperações para o desenvolvimento da aprendizagem. Para isso, é preciso força de vontade por parte dos professores para trabalhar com novas ferramentas de forma pedagógica para o bom desenvolvimento de uma aprendizagem significativa e infraestrutura necessária para aplicação dos recursos, só assim garantirá de forma prazerosa um ensino de qualidade.
\end{abstract}

Palavras-chave: Educação. Recursos Tecnológicos. Sala de aula. Ensino-aprendizagem.

\section{Uso dos Recursos Tecnológicos Atuais e sua contribuição no processo de Ensino-Aprendizagem na Escola Municipal Érico Veríssimo, Simões-PI}

\begin{abstract}
Resumo: O objeto de análise deste trabalho foi o uso das tecnologias atuais na Escola Érico Veríssimo município de Simões - PI e tem como objetivo estudar as contribuições dos recursos tecnológicos na escola, reconhecendo a importância desses recursos para a melhoria da qualidade do ensino aprendizagem. Analisar as contribuições dos mesmos para uma aprendizagem significativa, identificando os desafios dos professores e alunos diante do uso dessas tecnologias como mecanismo de ensino. Esse trabalho se constitui em uma pesquisa de campo e bibliográfica. Como ponto de partida o estudo foi fundamentado nas ideias de diferentes autores que versam a respeito do tema, dentre esses estudiosos temos Kiso (2007), Moran (2000) e Sousa (2010). Durante a pesquisa pode-se verificar que é possível inserir as tecnologias atuais nas aulas; bem como, incluir no planejamento o uso dessas ferramentas, inovando assim, a metodologia utilizada pelos educadores, fazendo cooperações para o desenvolvimento da aprendizagem. Para isso, é preciso força de vontade por parte dos professores para trabalhar com novas ferramentas de forma pedagógica para o bom desenvolvimento de uma aprendizagem significativa e infraestrutura necessária para aplicação dos recursos, só assim garantirá de forma prazerosa um ensino de qualidade.
\end{abstract}

Palavras-chave: Educação. Recursos Tecnológicos. Sala de aula. Ensino-aprendizagem.

\footnotetext{
${ }^{1}$ Graduado em Matemática e Normal Superior - UESPI. Especialista em Psicopedagogia - SOET. Mestrando em Educação pela Unisullivan University. E-mail: nerybraz@hotmail.com;

${ }^{2}$ Doutora em Sociologia pela - Universidade Federal da Paraíba-UFPB; Pós - Doutora em Letras pela - UFPB; Pesquisadora do Núcleo de Estudos em Ciência, Espiritualidade e Filosofia - URCA; Professora Aposentada da Universidade Regional do cariri - URCA.

E-mail: anna_crica@hotmail.com
} 
Id on Line Revista Multidisciplinar e de Psicologia

Id on Line Multidisciplinary and Psycology Journal

\section{Introdução}

Sabe-se que a informatização vem crescendo muito e que está sempre presente no cenário das discursões sociais, em constante processo de transformação. E percebe-se pouco uso destes recursos tecnológicos no ambiente escolar na nossa cidade. Diante dessa perspectiva, questiona-se: os recursos tecnológicos são de fato ferramentas que contribui para a qualidade do processo de ensino aprendizagem dos educandos e educadores?

Ao analisarmos o crescimento da informatização, mostra que a inclusão dos recursos tecnológicos na escola Érico Veríssimo, Simões-PI, pode contribuir para o melhor desenvolvimento na formação e socialização dos alunos e demais envolvidos na educação.

Diante disso, vê-se a necessidade em conscientizar a comunidade sobre a importância do uso dos recursos tecnológicos na sala de aula, por contribuir com a melhoria da qualidade do ensino entre educadores e educandos, no que se refere à formação intelectual e social destes indivíduos, além de contribuir para uma sociedade melhor e mais igualitária.

O uso das Tecnologias de Informação e Comunicação (TIC's) tornou-se fundamental nas últimas décadas e vem crescendo a cada dia devido à troca intensiva de informação e comunicação entre as pessoas. A globalização tem provocado diversas mudanças com relação ao desenvolvimento econômico, social e político, e com o uso das tecnologias atuais, a rotina escolar tem se transformado bastante, pois ela vem ajudando no desenvolvimento educacional, contribuindo para a melhoria da qualidade de ensino. Pensando nisso, resolveu-se pesquisar o uso das TIC's, a fim de observar se ela, de fato, teria uma contribuição significativa no processo de ensino-aprendizagem na escola Érico Veríssimo do município de Simões- PI.

O objeto de análise deste trabalho foi o uso das tecnologias atuais na Escola Érico Veríssimo município de Simões - PI, com a finalidade de perceber quais professores já usam essas tecnologias como práticas inovadoras, quais já percebem a contribuição dessas TIC's no processo de ensino aprendizagem e o porquê da resistência de alguns educadores quanto ao uso da mesma.

Esse trabalho se constitui em uma pesquisa com abordagem quanti-qualitativa, com estudo de conceitos baseados em material já elaborado, e como ponto de partida o estudo foi 
fundamentado nas ideias de diferentes estudiosos da área que idealizam as tecnologias atuais como sendo algo indispensável para a melhoria no ensino público, dentre outros estudiosos temos esses, Mendes (2008) Almeida (2002) e Moraes (2013), dentre outros.

A escolha dessa temática justifica-se por verificar a importância do uso das tecnologias no processo educacional, visto que a mesma vem acrescentando pontos positivos e inúmeros benefícios na educação, quando utilizado de forma correta, uma vez que professores e alunos têm uma intensa troca de conhecimentos, experiências e saberes.

Essa temática é de extrema relevância social e acadêmica, contudo as tecnologias de informação e comunicação precisam ser inseridas não só no contexto escolar, mas também nos diversos setores da sociedade.

\section{As Tecnologias Atuais E Suas Contribuições No Processo De Ensino - Aprendizagem}

$\mathrm{Na}$ atualidade, a educação não pode ser concebida somente em sala de aula, pois não se sustentará com uma pedagogia baseada somente em métodos tradicionais. O profissional em educação deve procurar formas de contribuir significativamente com seu alunado.

As tecnologias atuais diminuem empecilhos que impedem o progresso do indivíduo, uma constante também incorporada na área da educação. Como mediador deste processo na educação, o professor deverá lançar desafios e experiências que envolvam seus alunos e que os levem a vencer suas dificuldades, principalmente no âmbito da aprendizagem. Sendo assim, poderá desenvolver uma metodologia que virá atender anseios de seu público de trabalho - os alunos. Para tanto, poderá encontrar diversas formas de se apropriar de recursos digitais como ferramentas de ensino e aprendizagem.

A tecnologia tem se apresentado como ferramenta relevante nas diversas ações do homem em sociedade. Não é diferente, a importância que assume também dentro das escolas no processo de ensino aprendizagem.

A Tecnologia da Informação e Comunicação (TIC), ou as Tecnologias Atuais, de acordo com Mendes (2008) é um conjunto de recursos tecnológicos, integrados entre si, que proporcionam a comunicação em várias situações da vida em sociedade. São tecnologias usadas para reunir, distribuir e compartilhar informações e constitui um conjunto de técnicas e 
Id on Line Revista Multidisciplinar e de Psicologia

Id on Line Multidisciplinary and Psycology Journal

ferramentas tais como computador e internet que já são utilizadas nas escolas para viabilizar a efetivação das atividades didáticas. São instrumentos que, dependendo da proposta pedagógica, podem tornar a aula dinâmica e atrativa para aluno e professor.

De acordo com Almeida (2002), o professor ao incorporar as tecnologias atuais aos métodos e estratégias além de desenvolver habilidade de uso das mesmas, estabelece uma ligação entre esse domínio à prática pedagógica transformando assim sua atuação em sala de aula. A adequação da rotina didática aos instrumentos tecnológicos possíveis nesse contexto possibilita a inovação do processo de ensino e aprendizagem.

Há instituições que apontam como dificuldades para o uso das TIC's nas escolas a disponibilidade destes recursos que, quando existe é em quantidade inferior ao necessário para atender a demanda de professores e alunos. Outra dificuldade é a falta de preparação dos educadores para atuar com estes recursos. Alguns utilizam apenas conforme tem um conhecimento resumido, outros, não conhecem e apresentam dificuldades ou recusa em aprender a utilizar.

O quadro de escolas públicas do município de Simões que utilizam as TIC's atuais é crescente a cada ano, porém de forma lenta, e quando se trata de prática diária dessas ferramentas, ainda é muito pequena a utilização e existe alunos que se quer têm acesso a esses instrumentos dentro da suas escolas. Por conta disso, pretende-se tornar o uso das TIC's atuais mais frequentes e da maneira correta onde a prática do educador e a participação do aluno no processo de aprendizagem sejam amplamente viabilizadas por estes recursos.

No cenário educacional dos dias de hoje as tecnologias atuais vem sendo alvo de grandes debates, porque ainda se vê grande resistência de muitos profissionais em adequar a sua pratica pedagógica aos avanços tecnológicos da atualidade, sem querer fugir do tradicionalismo.

Nesse estudo evidencia-se a necessidade de desenvolver dentro da conjuntura da escola, uma proposta baseada no diálogo e, debatendo ideias sobre a inserção dessas ferramentas para que os envolvidos no processo educativo sintam-se motivados e aptos a trabalharem com esses recursos, tornando assim, suas aulas mais dinâmica e prazerosa para que os alunos sintam-se mais motivados e possam melhorar seus desempenhos no processo de aprendizagem. 
Id on Line Revista Multidisciplinar e de Psicoloqia

Id on Line Multidisciplinary and Psycology Journal

\section{Procedimentos Metodológicos e seus Resultados}

A observação foi feita na escola municipal Érico Veríssimo - Simões PI. Os sujeitos pesquisados foram professores, diretores, coordenadores e alunos da referida escola. A Escola supracitada funciona em dois turnos, manhã e tarde, do infantil ao fundamental II, composta por 638 alunos e 48 funcionários. Para a coleta de dados foi feito visitas à escola e observação. Além de aplicação de questionários com perguntas abertas e fechadas para 30 membros entre alunos e funcionários.

Os procedimentos metodológicos necessários à realização deste trabalho partem de uma abordagem quanti-qualitativa, com estudo de conceitos baseados em material já elaborado, em autores que versam a respeito do tema e através de estudo de campo para o aprofundamento da temática.

A observação aconteceu na escola municipal Érico Veríssimo Simões PI. Os sujeitos pesquisados foram professores, diretores, coordenadores e alunos. A Escola pesquisada funciona em dois turnos, manhã e tarde, do infantil ao fundamental II, composta por 638 alunos e 48 funcionários, sendo 39 professores, 03 auxiliares de sala, 03 coordenadores, 01 diretor, 01 secretaria, 01 auxiliar de secretaria.

A pesquisa foi realizada através de observação e aplicação de questionários com perguntas abertas e fechadas para 30 membros entre alunos, professores e gestor. Para a coleta de dados foi utilizados técnicas de entrevistas, visitas à escola e observação. Houve a necessidade de adentrar ao convívio escolar com o intuito de observar, investigar e descobrir se os profissionais de educação da escola estão preparados para utilizar as tecnologias.

Foi feito levantamento das pessoas que usam as tecnologias atuais como práticas inovadoras, as quais já percebem a contribuição das TIC'S no processo de ensino aprendizagem e o porquê da resistência de alguns educadores quanto ao uso da mesma.

Segundo alguns entrevistados, o uso das TIC's é necessário no ambiente escolar, uma vez que enriquece as atividades propostas e desenvolve o interesse e interatividade dos alunos.

Foi feita a comparação dos resultados obtidos na observação, a fim de analisar a importância de inserir as Tecnologias da Informação e Comunicação na Escola Érico Veríssimo, enumerando as dificuldades encontradas pelos professores ao executar as TIC'S em seus planejamentos pedagógicos. 
Id on Line Revista Multidisciplinar e de Psicologia

Id on Line Multidisciplinary and Psycology Journal

Diante da analise das respostas dos Professores e Alunos, verificou-se que o uso dos recursos tecnológicos na sala aula pode favorecer muito para a melhoria da qualidade do ensino aprendizagem entre educador e educando, visto que essas ferramentas ajudar a fugir das aulas tradicionais, sempre chamando mais a atenção do aluno, e isso faz com que as aulas se tornam mais atrativas.

Para Moraes (2013), “o simples acesso à tecnologia, em si, não é o aspecto mais importante, mas sim, a criação de novos ambientes de aprendizagem e de novas dinâmicas sociais a partir do uso dessas novas ferramentas".

Isso mostra que é preciso o professor conhecer e saber incorporar esses recursos nas suas aulas, não como um mero transmissor de informações, mas de forma que a facilitar a construção do conhecimento ao educando, e assim atingir os objetivos propostos.

Os alunos entrevistados gostaram e acharam mais proveitosas às aulas mediadas pelos recursos tecnológicos, pois modifica a forma do professor ensinar, já que aula formal muitas vezes se torna cansativa e muito repetitiva. Neste sentido, o professor deve ser o maior incentivador, deve buscar sempre inovar suas aulas, e assim contribuir para um melhor aprendizado de seus educandos.

Os resultados a seguir foram obtidos a partir de questionários respondidos pelo gestor e pelos professores participantes da pesquisa. De acordo com as respostas do gestor da escola, as TIC's presentes na instituição são poucas, levando em consideração o número de alunos e professores que precisam dessas tecnologias. A instituição conta com datahow, televisão, computador, impressora, aparelho de DVD, lousa digital, microsystem, microfone, tela de projeção e caixa de som, sendo que nem todas são utilizadas, como a lousa digital, por não ter nem um profissional na instituição que saiba utilizar a ferramenta e por não terem recebido instruções para a utilização deste meio em favor do trabalho educacional.

O gestor relata que dá apoio aos professores que se dispuserem a utilizar as tecnologias de informação e comunicação em sala de aula e afirma usaras tecnologias como método de comunicação e informação através do envio de documentos, assim como organização dos trabalhos realizados, tendo como ferramenta principal o computador. De acordo com Tajra (2001), a escola, além de direcionar as fontes de pesquisas para os recursos tecnológicos já existentes como livros, enciclopédias, revistas e jornais, pode adquirir outras fontes de aprendizagem como, por exemplo, o computador. 
O diretor da escola e a coordenação ressaltam que promovem a organização dos projetos que são utilizados com os recursos tecnológicos e também articulam a manutenção dos equipamentos de acordo com a utilização deles pelos professores e alunos. É importante destacar que a equipe escolar - gestão, coordenadores e o corpo docente - é responsável pela inserção dessas ferramentas no projeto pedagógico da escola, e por articular as mídias no ambiente escolar de forma que desperte interesse e prazer nos alunos, ao desenvolver de suas atividades interdisciplinares.

Alguns professores destacaram que fazem uso do retroprojetor, pen drive e caixa de som para exibir os conteúdos relacionados à aula, projetar vídeos, imagens, filmes, textos entre outros. Jesus et al. (2012), destacam que, para o sucesso na implantação dos recursos tecnológicos em sala de aula, é importância definir estratégias de entrosamento entre o corpo docente com a equipe de suporte técnico, já que ambos os trabalhos se complementam mutuamente. A partir dessa analise, mostra a importância da escola ter um suporto técnico, proporcionando as condições que favoreça o uso destes recursos.

Ainda no relato dos professores, percebe-se que alguns encontram dificuldades para trabalhar conteúdos utilizando os recursos tecnológicos, na questão do manuseio. Outros disseram não ter dificuldade nenhuma. Já os alunos não citaram dificuldades em lidar com essas ferramentas, e que já fizeram uso do retroprojetor para apresentar trabalhos orientados pelo educador, citaram também que, o uso do celular é proibido dentro da escola.

A respeito dessas habilidades em relação aos recursos tecnológicos, Pereira (2011, p.14) diz que:

\begin{abstract}
As habilidades desenvolvidas pelos alunos, se dá pelo fato de terem crescido em uma sociedade permeada de recursos tecnológicos, por isso manipulam e dominam com maior rapidez e desenvoltura as tecnologias que seus professores. Mesmo pertencentes a camadas menos favorecidas, os alunos têm contato com recursos tecnológicos na rua, na televisão, entre outros. Sua percepção sobre tais recursos torna diferente, de quem cresceu numa época onde essas ferramentas eram muito restritas.
\end{abstract}

O papel do professor é indispensável, pois a sua mediação será fundamental, tendo em vista que os alunos usam esse recurso nas ruas para outros fins, com isso os professores poderão guiá-los para que possam usar suas habilidades com esses recursos, buscando melhorias para uma aprendizagem significativa. 
Id on Line Revista Multidisciplinar e de Psicologia

Id on Line Multidisciplinary and Psycology Journal

Mercado (1999), aponta alguns fatores que provoca resistência nos professores, como a insegurança, a acomodação pessoal e profissional, o medo de danificar e as condições socioeconômicas.

Nessa perspectiva, percebe que vários são os fatores que influencia na não utilização dos recursos tecnológicos, e para sanar essa resistência, o mais ideal seria uma capacitação de manuseio para estes profissionais educadores, unindo o conhecimento pedagógico com a prática do uso das ferramentas tecnológicas para que então, possam desenvolver com qualidade a aprendizagem de seus alunos.

É possível comparar os resultados obtidos na observação, a fim de analisar a importância de inserir as Tecnologias da Informação e Comunicação na escola Érico Veríssimo, enumerando as dificuldades encontradas pelos professores ao executar as TIC'S em seus planejamentos pedagógicos.

Considerando-se o uso desta experiência satisfatória, uma vez que as tecnologias atuais é algo de interesse do alunado, e quaisquer mecanismos que as envolvam, numa situação comunicacional, de interação entre estes atores na educação, será tida por eles como interessante e envolvente. O que fará com que seu trabalho como educador, possa fluir diminuído os desafios que envolvem a prática da docência.

\section{Opiniões Dos Professores Da Escola, Quanto Ao Uso Das Tic's}

Segundo os professores da Escola Érico Veríssimo, o uso das TIC's é necessário no ambiente escolar, uma vez que enriquece as atividades propostas e desenvolvem o interesse e interatividade dos alunos. Dos vintes professores, quatorze relatam que fazem pouco uso das Tecnologias de Informação e Comunicação por ter dificuldades e sempre precisar de auxílio para utilizar os recursos; os outros seis professores participantes fazem uso de data show, televisão e aparelho de DVD, pelo menos, duas vezes por semana. Nota-se, que $70 \%$ dos professores em pesquisa só utilizam as ferramentas tecnológicas de informação e comunicação com auxílio e $30 \%$ fazem uso, pelo menos, duas vezes por semana em suas aulas. Contudo, a gestão, assim como os professores ainda não tiveram a ideia de promover cursos que os atualizem e capacitem com relação ao manuseio dessas tecnologias. 
Gráfico 1: Uso da TIC's pelos professores.

\section{Uso das TICS pelos professores}

n usam TICs somente com auxílio usam TICs pelo menos duas por semana

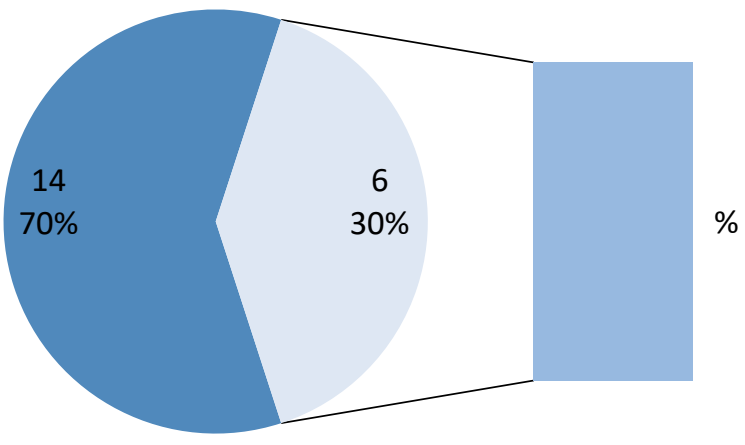

Fonte: Dados da pesquisa do autor (2016).

Desse modo, todos os docentes afirmam ter alguma dificuldade ao utilizar as ferramentas tecnológicas presentes na instituição, relatam não estar preparados e capacitados para desenvolver atividades escolares usando estes recursos como deveriam e que indiscutivelmente os mais utilizados em sala de aula, na prática de atividades, é o computador, o data show, a televisão e o aparelho de DVD. Entretanto, sua prática de sala de aula se dá praticamente por meio de apresentação de slides, vídeos e atividades fotocopiadas e impressas. A partir da pesquisa, pode-se afirmar que todo professor inserido nessa escola, é consciente de sua carência e falta de qualificação para usar adequadamente os diferentes tipos de ferramentas pertencentes à instituição e, inclusive, não utilizam como deveriam por não terem habilidade com relação ao manuseio do equipamento.

Em referência aos conteúdos ministrados em sala de aula, alguns professores dizem que, sempre que podem, elaboram suas aulas utilizando os recursos tecnológicos adquiridos, como forma de dinamizar a aula, trazendo para isso, vídeos, filmes e outras possibilidades que provocam mudança na rotina escolar.

O objetivo, segundo eles, é desenvolver a capacidade crítica para lidar com a grande variedade de informações e comunicação. Conforme Sousa (2010), o uso das TIC's deve ser 
Id on Line Revista Multidisciplinar e de Psicologia

Id on Line Multidisciplinary and Psycology Journal

encarado de forma prazerosa, para que docente e discente sintam-se à vontade no seu manuseio e que os resultados possam ser gradativos, mas sempre promissores para a aprendizagem.

De acordo com todos os professores participantes dessa pesquisa, a escola necessita de um laboratório de informática e de internet, pois na falta da internet os equipamentos ficam sem utilidade, gerando um grande problema para a inserção dessas ferramentas no ambiente escolar. A esse respeito, Moran (2002) aponta que a internet é, entre tantos, mais um recurso para aprimorar a metodologia de ensino, e, se bem explorada proporciona uma vasta quantidade de ferramentas que podem enriquecer o processo ensino- aprendizagem.

Observou-se na inserção de campo que os alunos e professores da Érico Veríssimo necessitam trabalhar com novas ferramentas das tecnologias atuais que incrementem a aprendizagem de ambos os lados. Ao serem questionados sobre o que precisam para utilizarem ferramentas tecnológicas, os relatos mais marcantes dos alunos foram: "queremos mais acesso a internet na escola"; "precisamos de internet com mais frequência"; e "os professores devem ser treinados pra saberem mexer direito com essas ferramentas e ensinarem para os alunos".

O processo de inclusão ao mundo digital é crescente e essencial na divulgação de informações no mundo contemporâneo. Kiso (2007) coloca que mídia social parte das tecnologias e instrumentos virtuais usadas para o compartilhamento de opiniões, ideias, experiências e perspectivas, no intuito da interação e disseminação de informações variadas.

As falas apontam que todos estão engajados em trabalharem melhor com tecnologia e informática, mas se mostram preocupados em terem mais acesso a internet e serem bem treinados para utilizarem bem esta modalidade de disseminação de conhecimento.

É preciso tornar mais viável a relação entre a prática pedagógica e as TICs atuais, com esse pensamento, os educadores que responderam os questionários, sugerem um número maior de recursos tecnológicos nas escolas garantindo a tranquilidade de utilização; sugerem ainda, uma Proposta Pedagógica que garanta espaço nas atividades letivas para os professores possam levar seus alunos a executarem algumas atividades com estes recursos. 
Id on Line Revista Multidisciplinar e de Psicologia

Id on Line Multidisciplinary and Psycology Journal

\section{Considerações Finais}

Com base no levantamento realizado, através dos resultados obtidos, nota-se que os recursos tecnológicos são fundamentais na sala de aula, inseridos de forma correta, pode contribuir para a melhoria da qualidade do ensino, uma vez que eles têm o poder de modificar as aulas.

Verificou-se ainda que nem todos os professores fazem uso destes recursos e os fatores apontados foram à falta de habilidades e de suporto técnico. Com isso, vê-se a necessidades de maiores investimentos por parte do governo, na capacitação de professores e no apoio de suporte técnico, para que o uso destes recursos possa favorecer o trabalho do professor e contribuir para a melhoria da qualidade do processo de ensino aprendizagem.

De modo geral, percebe-se que a escola objeto dessa pesquisa tem vários recursos tecnológicos de informação e comunicação em seu poder, os quais podem contribuir no processo ensino-aprendizagem, mas ainda são poucas para atender o número de professores e alunos constituintes na instituição. Os educadores demonstraram saber da importância das TIC's no processo educacional e da responsabilidade em desenvolver atividades adequadas com o uso das mídias com recursos metodológicos para a construção do conhecimento e aprendizagem nos alunos.

Constatou-se, ainda, que os professores têm consciência de que ainda não estão preparados para lidar com esses recursos tecnológicos, mas mesmo com as dificuldades apresentadas eles empregam algumas ferramentas presentes na escola, exceto a lousa digital que nunca foi usada por falta de conhecimento acerca do seu manuseio por parte de todos os profissionais da instituição.

No entanto, é necessário a qualificação desses profissionais para poderem utilizar as TIC's de forma consciente, assim como que eles percebam que também precisam buscar a qualificação, em seu próprio benefício, afinal a formação continuada deve estar sempre presente na vida profissional dos professores.

O professor não pode ignorar as vantagens que a tecnologia pode lhe fornecer. Sua prática pedagógica inclui uso de softwares educacionais, ambientes virtuais e ferramentas digitais de comunicação, mecanismos eficientes de tecnologia no ambiente escolar. Pois são 
Id on Line Revista Multidisciplinar e de Psicologia

Id on Line Multidisciplinary and Psycology Journal

importantes aliados na prática pedagógica, proporcionando ao professor interação com seus alunos.

É relevante que o sistema educacional disponha de material em quantidade satisfatória e principalmente que capacite o profissional de educação para manusear os recursos, sendo que, dentro desta preparação haja principalmente, o incentivo.

Enfim, considera-se o uso das tecnologias atuais no ambiente escolar como uma ferramenta pedagógica fundamental para o processo ensino-aprendizagem, pois proporciona vários benefícios para a educação, quando utilizadas de forma adequada. Por isso, a capacitação profissional é indispensável em qualquer área, principalmente no magistério. As tecnologias invadiram os diversos setores sociais e avançam a cada dia, com isso a educação tende a se transformar, buscando incorporar novos elementos com o intuito de acompanhar a era da informatização. Assim sendo, as escolas devem adaptar o currículo e a essa realidade.

O professor adquire papel relevante nas transformações dos métodos de ensino, cabendo a esses profissionais despertar o interesse dos alunos, mediando à construção do conhecimento, por meio do uso desses novos recursos. Portanto, as tecnologias atuais representam um novo paradigma educacional e os professores por sua vez, devem aperfeiçoar seus conhecimentos diante das tecnologias modernas à medida que a sociedade se modifica.

Através da pesquisa realizada verificou-se que as Tecnologias atuais é uma ferramenta de apoio na construção do aprendizado promovendo aos alunos mais interesse, dedicação, participação e motivação. Mais vale ressaltar que a necessidade de investimentos e formação continuada nesse aspecto é essencial para que os educadores possam lecionar usando estratégias criativas, modernas e produtivas.

Diante da reflexão realizada nesta pesquisa, conclui-se que um profissional de educação atuante deve interagir cada vez mais com o meio, com a contemporaneidade e para tanto, novas experiências serão imprescindíveis e decisivas tornando suas aulas mais atrativa e prazerosa.

Nesse sentido, Mercado (1999) afirma que o uso da TIC pode contribuir para auxiliar os educadores e sem sua tarefa de apenas transmitir o conhecimento e adquirir várias maneiras de ensinar, cada vez mais criativas e dinâmicas, auxiliando o professor em novas descobertas e investigações.

Acredita-se que servira para motivar os alunos na aquisição de conhecimento e na forma de aprender, tornando-se um importante instrumento de apoio no processo ensino- 
aprendizagem. Vale destacar que, embora os professores sejam a peça chave desse processo, a inserção dessas tecnologias no ambiente escolar desperta mais interesse e curiosidade nos alunos, uma vez que eles vivem esse mundo tecnológico em seu dia a dia.

\section{Referências}

ALMEIDA, M. E. B. Educação, projetos, tecnologia e conhecimento. São Paulo: PROEM, 2002.

JESUS, P. M; GALVÃO, R. R. O; RAMOS, S.L. As Tecnologias Digitais de Informação e Comunicação na Educação: desafios, riscos, e oportunidades, CEFET-MG, 2012. p. 107

KISO, R. Mídia Social - A ascensão da plataforma do consumidor como mídia. 2007. Disponível em : http://www.focusnetworks.com.br/focusview/midia-social-a-ascensao-daplataforma-do-consumidor-como-mida / Acesso em: 10 de junho de 2016.

MENDES, A. TIC - Muita gente está comentando, mas você sabe o que é? PortaliMaster,mar.2008. Disponívelem:http://imasters.com.br/artigo/8278/gerencia-de-ti/ticmuita-gente-esta-comentando-mas-voce-sabe-o-que-e/ Acesso em: 27 Agosto de 2016.

MERCADO, Luis Paulo Leopoldo. Formação Continuada de Professores e Novas Tecnologias. Maceió: Edufal, 1999. p. 33

MORAES, M. C. apud Jacinto M. L. Integração das tecnologias de informação e comunicação. Artigo publicado em 2013. Disponível em http://lucianoupmtz.blogspot.com.br/2013/06/integracao-das-tecnologias-de.html consulta realizada em 09.06.2016 às 17:19. P. 53

MORAN, J. M. Mudar a forma de ensinar e aprender e aprender com tecnologias. Revista Intenções, v. 5, n 9, p. 52-72, 2000. Disponível em: < http://www.eca.usp.br/prof/moran/site/textos/tecnologias_eduacacao/uber.pdf Acesso em: 29 de maio de 2016.

PEREIRA, B.T. O uso das tecnologias da informação e comunicação na prática pedagógica da escola. Artigo publicado em 2011. Disponível em http://www.diaadiaeducacao.pr.gov.br/portals/pde/arquivos/1381-8.pdf consulta realizada em 05.06.2016 às 15:29. p. 14.

SOUSA, S.R. de. Educação e as novas tecnologias da informação e comunicação- NTIC's. UFPI, Teresina, 2010. 
TAJRA, Sanmya Feitosa. Informática na educação: novas ferramentas pedagógicas para o professor na atualidade. 3. ed. São Paulo: Érica, 2001. Disponível em: <http://midia.unit.br/enfope/2013/gt5/ainsercaotecnologiaeducacao mudanças papel_docente .pdf> Acesso em: 03 de maio de 2016.

\section{Como citar este artigo (Formato ABNT):}

CARVALHO, N.B.; CARVALHO, A.C.F. O Uso dos Recursos Tecnologicos atuais e sua contribuição no processo de Ensino-Aprendizagem na Escola Municipal Érico Veríssimo, Simões-PI. Id on Line Revista Multidisciplinar e de Psicologia, Janeiro de 2017, vol.10, n.33, Supl 2. p. 112-125. ISSN: 1981-1179.

Recebido: 03/01/2017

Aceito: 05/01/2017 